\title{
A teoria da dependência: reflexões sobre uma teoria latino-americana
}

Gustavo Javier Castro Silva ${ }^{1}$

\begin{abstract}
Resumo
O artigo faz um estudo de história das idéias sobre a Teoria da Dependência, um enfoque teórico que abrangeu diferentes aspectos da reflexão e da pesquisa social na América Latina, na segunda metade do século XX. A origem da Teoria da Dependência encontra-se, na década de 50, no pensamento elaborado pelo argentino Raúl Prebisch e outros teóricos vinculados à Comissão Econômica para América Latina (CEPAL), os quais são denominados como teóricos da "velha dependência". Na metade da década de 60, numa segunda fase, produzir-se-á um ressurgimento da crítica marxista às perspectivas convencionais do desenvolvimento, surgindo os teóricos da "nova dependência”. Na terceira fase observa-se a penetração da Teoria da Dependência em círculos acadêmicos dos centros. O trabalho centra sua análise em teóricos da dependência latino-americanos e que, de alguma ou outra forma, fizeram uso de categorias marxistas.
\end{abstract}

Palavras-chave: Teoria da dependência, Pensamento Latino-americano, CentroPeriferia

\section{Introdução}

O objetivo deste artigo consiste em fazer um breve estudo de história das idéias sobre a Teoria da Dependência, um enfoque teórico que abrangeu diferentes aspectos da reflexão e da pesquisa social na América Latina.

É pressuposto do trabalho, que as novas contribuições nas ciências sociais devem ter clareza sobre sua conformação histórica e consciência das elaborações teóricas e conceituais que contribuíram no desenvolvimento das mesmas.

A Teoria da Dependência constitui um capítulo fundamental nas ciências sociais latino-americanas por ser a primeira contribuição proveniente dos países em vias de

\footnotetext{
Doutor em Sociologia pela Universidade de Brasília. Professor do UNIEURO. E-mail: <gustavo@unieuro.com.br>.
} 
desenvolvimento que forneceu ferramentas conceituas importantes para o estudo do desenvolvimento e que, ainda, influenciou o ambiente acadêmico dos países desenvolvidos. Cabe lembrar que a Teoria da Dependência centra sua análise nos países periféricos, a partir de uma visão crítica da relação entre esses países e os centrais.

A origem da Teoria da Dependência encontra-se, na década de 50, no pensamento elaborado pelo argentino Raúl Prebisch e outros teóricos vinculados à Comissão Econômica para América Latina (CEPAL), os quais realizam uma crítica às explicações convencionais do desenvolvimento, a partir de uma perspectiva essencialmente econômica. Estes autores são denominados como teóricos da "velha dependência".

Na metade da década de 60, numa segunda fase, produzir-se-á um ressurgimento da crítica marxista às perspectivas convencionais do desenvolvimento, crítica que também será dirigida aos postulados de Prebisch e os “cepalinos”. Estas críticas também se estenderam às análises reducionistas provenientes da Ciência Política e da Sociologia. Nesse momento surgem os teóricos da "nova dependência", entre os quais, em diferentes vertentes, podem ser mencionados André Günter Frank, Fernando Enrique Cardoso, Enzo Faletto, Theotônio dos Santos, Celso Furtado, Ruy Mauro Marini, entre outros. A maioria desses autores, em maior ou menor grau, segue a metodologia do materialismo histórico-dialético. Porém, podem ser identificadas diferenças importantes entre eles, como as referentes à relação dependênciadesenvolvimento ou à importância atribuída aos fatores externos ou internos em uma situação de dependência específica.

A terceira fase do desenvolvimento da teoria da dependência é denominada por Fernando Henrique Cardoso como a etapa do "consumo". Trata-se da descoberta dessa teoria no âmbito acadêmico dos países centrais.

Nesta terceira etapa, no início da década de 70, distinguem-se três vertentes. A primeira é o "confusionismo", isto é, o uso de parte da terminologia da dependência, mas não assim seu conteúdo. Nesta vertente destacam-se Guy F. Erb e Harry R. Targ.

Em segundo lugar, surge o "distorsionismo", que consiste na adoção de parte da terminologia da dependência, mas eliminando conscientemente alguns dos seus conceitos, tais como os elementos históricos e/ou de classe. Aplica-se a dependência ao estudo das relações de poder entre os estados, considerando-a, no melhor dos casos, só 
como uma variável externa. Os trabalhos de Robert Pacckenham e David Ray estão dentro desta linha.

Por último, nesta terceira fase de penetração da Teoria da Dependência em círculos acadêmicos dos centros, surgem algumas contribuições interessantes que tentam manter coerência com o substancial dessa teoria. Alguns dos autores que produzem neste sentido são Samir Amim, Walter Rodney, Arghiri Emmanuel e Keith Griffin.

A Teoria da dependência, numa síntese apertada, afirma que a unidade nacional ou regional somente pode ser entendida em conexão com sua inserção no sistema político-econômico mundial. Em outras palavras, a economia dos países periféricos está condicionada pelo desenvolvimento e expansão das economias dos países centrais. Também é fundamental ter em consideração o momento e a forma na qual se realiza a inserção no sistema capitalista global e as análises das características específica internas das sociedades dependentes.

Muito se tem escrito e pesquisado sobre a Teoria da Dependência, tanto nos países periféricos, sobre tudo na América latina, quanto nos países centrais. Porém, muitas vezes se tem produzido confusões teóricas, devido, fundamentalmente, à precária sistematicidade que caracterizou a literatura da dependência, à dinâmica interna de uma teoria não suficientemente finalizada, às mudanças produzidas no sistema político-econômico mundial, às transformações internas das sociedades dependentes e, outras vezes, devido a críticas de caráter ideológico.

A Teoria da Dependência perdeu a eficácia teórica que teve até a metade da década de 80 , mas é indubitável que esta teoria teve uma importância fundamental para o entendimento das características que assume o desenvolvimento nos países periféricos ao sistema econômico global. Este artigo centrará sua análise em teóricos da dependência latino-americanos e que, de alguma ou outra forma, fizeram uso de categorias marxistas. 


\section{A Teoria da Dependência.}

A nossa intenção não é determos no exame de cada um dos enfoques da Teoria da Dependência, mas de determinarmos, de modo geral, algumas idéias e pressupostos básicos destas diferentes perspectivas, com o objetivo de apresentar uma visão global sobre o assunto.

Para autores como Frank e dos Santos, um fato capital dentro da dependência é a ligação estrutural existente entre os fatores domésticos e os fatores externos. A condição de dependência não pode ser considerada só na base de fatores externos. Frank afirma que: "a dependência não pode ser considerada como uma relação meramente 'externa' imposta de fora a todos os latino-americanos e contra a sua vontade, mas que a dependência é igualmente uma condição 'interna' e integral da sociedade latinoamericana, que determina a burguesia dominante na América Latina, e, por sua vez, é consciente e gostosamente aceita por ela." 2

Esta tese é muito importante, pois, partindo dela, conclui-se que a burguesia nacional não tem condições de oferecer uma alternativa autônoma de desenvolvimento, dado que o caráter integral da dependência faz com que ela mesma seja dependente.

Sobre o ponto anterior, Luciano Tomassini afirma que "Uma contribuição especial desta escola radica na sua apreciação de que os mecanismos através dos quais se produz a relação de dependência incluem a existência de interesses comuns, alianças políticas e estratégias convergentes entre os segmentos capitalistas (majoritários) dos países industrializados e os mesmos setores (minoritários) dos países em desenvolvimento." 3

Este é um ponto que distingue os teóricos marxistas da dependência de outras correntes $^{4}$. Existe, então, nos teóricos da dependência uma aceitação da importância que

\footnotetext{
${ }^{2}$ A. G. Krank. Lumpenburguesía: Lumpendesarrollo. Santiago: Editorial Prensa Latinoamericana, 1970, p. 15

${ }^{3}$ Luciano Tomassini. Teoría y Práctica de la política Internacional, Santiago: Ediciones Universidad Católica de Chile, 1989, pp. 101-102.

${ }^{4}$ Luciano Tomassini distingue três grandes correntes da Teoria da Dependência: "A primeira, originada nos trabalhos elaborados por Raúl Prebisch no princípio dos anos cinqüenta, centrada nas assimetrias inerentes às relações centro-periferia... A segunda implica um aprofundamento da análise original de Prebisch, e nela se analisam conjuntamente os aspectos econômicos, políticos e sociais do fenômeno da dependência, como também seus elementos externos e internos, ultrapassando desta maneira a ênfase inicial em seus aspectos econômicos e nas suas origens internacionais... A terceira mostra uma maior proximidade com a análise marxista, com o qual há coincidências ocasionais nas correntes anteriores, devido a sua comum base epistemológica, que consiste em considerar o sistema internacional -ou mais
} 
tem a idéia de que a sociedade dos países dependentes é uma sociedade estruturada em classes, e na qual, portanto, se encontram os conflitos inerentes à luta de classes.

Para esclarecer e sintetizar os elementos básicos da teoria da dependência convém referirmo-nos a dois conceitos que J. Caporaso tem denominado como dependence e dependency ${ }^{5}$.

Entende-se o primeiro conceito entende-se simplesmente como uma relação externa. Isto é, a partir do suposto de que entre os Estados-nações existem assimetrias e simetrias, tentando demonstrá-las e analisá-las. Este conceito, para estudar as relações internacionais, entende que as dependências setoriais entre os Estados-nações não podem ser somadas umas às outras, constituindo assim uma situação total e integral de dependência de um Estado-nação com relação a outro. Em fim, a dependência entendida como dependence fica só no plano de uma dependência externa, enquanto que o objeto de sua explicação constitui-se a influência internacional.

Diferentemente, dependency refere-se ao processo pelo qual os países menos desenvolvidos são incorporados ao sistema capitalista global. Em outras palavras, a Teoria da Dependência, tal qual é entendida por autores como Frank, dos Santos ou Cardoso, tenta esclarecer o processo de integração da periferia ao sistema capitalista internacional, colocando especial atenção nos problemas para o desenvolvimento que este processo implica.

Desta maneira, a Teoria da Dependência, contrariamente à dependência entendida só como uma relação externa, destaca o fato de que os atores que participam do processo de dependência não são só os Estados-nações, mas também "a estrutura de classes que se apresenta em um Estado-nação, as alianças entre as classes locais e o capital internacional, bancos, indústrias e firmas." 6

O objeto de análise da teoria da Dependência é o desenvolvimento. Mas, não se estuda o desenvolvimento só como o incremento no produto total da economia, elemento que também é considerado. Mais importante que isto, e fazendo da Teoria da Dependência uma análise mais global da sociedade - não somente considerando os

especificamente o sistema capitalista mundial- como uma estrutura global que determina o comportamento, os benefícios e os custos de suas diferentes partes integrantes". Luciano Tomassini, op. cit., pp. 104-105.

${ }^{5}$ Ver: James Caporaso e Behrouz Zare. "An Interpretation and Evaluation of Dependence Theory", em Heraldo Muñoz (ed.), From Dependency to Development: Strategies to Overcome Underdevelopment and Inequality, Boulder, Colorado: Westview Press, 1981.

${ }^{6}$ Ibid., p. 44. 
aspectos econômicos, mas fundamentalmente elementos culturais, históricos, políticos e sociológicos -, estuda-se o desenvolvimento também no seu aspecto qualitativo, quer dizer, levando em consideração aspectos tais como: se o crescimento vai acompanhado de um incremento ou diminuição da desigualdade, ou se o crescimento produz mais ou menos marginalização, ou se este crescimento vem acompanhado de formas mais democráticas ou autoritárias de governo e de estrutura social.

A Teoria da dependência, então, vai além do aspecto econômico e introduz outros que não parecem estar identificados com o funcionamento da economia. Theotônio dos Santos, criticando as análises que ficam somente no aspecto econômico, diz: "Aqui existe um importante fator de percepção social: pode-se entender como uma 'crise' uma corrida à bolsa, mas não consideram justo conceber como uma crise a existência de 6 a 8 milhões de desempregados, como acontece hoje nas 'pequenas' variações recessivas do sistema. Há que apontar estas armadilhas lingüísticas para explicar por que não aceitamos tais 'precisões' terminológicas. Por esta razão, não queremos separar os aspectos econômicos dos sociais e políticos. Neste trabalho, buscase, exatamente, ligá-los entre si com o objetivo de ressaltar suas inter-relações e interdependências recíprocas, sem negar, embora, a autonomia relativa dos aspectos econômicos." 7

Um elemento essencial dentro de uma definição de dependência é o fato de as economias nacionais dos países periféricos estarem atrofiadas, e, para funcionar como tais, estas economias necessitam do circuito capitalista internacional. Paralelamente, e deforma dialética, a este elemento se devem acrescentar os importantes aspectos internos da dependência, que servirão para chegar à sua correta definição.

Os aspectos internos da dependência referem-se à fragmentação interna que apresentam as sociedades dependentes. Sem este fator não estamos diante de uma situação estrutural de dependência, dado que só o fato da dependência externa, desacompanhada de fragmentação interna, está mais perto do que se tem definido como dependence.

A Teoria da Dependência não tem presente só os fatores internos e os externos. "O conceito de dependência, segundo uma grande percentagem de estudiosos da 'nova dependência', deve ser visualizado a partir de uma perspectiva histórico-estrutural que

\footnotetext{
${ }^{7}$ Theotônio dos Santos, La Crisis Norteamericana y América Latina, Santiago: Editorial Prensa Latinoamericana, 1971, p. 25.
} 
ultrapasse a distinção analítica entre fatores internos e externos que tende a ocultar a unidade estrutural existente entre ambos. $\mathrm{O}$ conceito de dependência supera a dicotomia 'externo-interno', 'mundo desenvolvido-mundo subdesenvolvido', incorporando-os em uma só estrutura, o sistema capitalista internacional." 8

O elemento anterior é importante, pois permite distinguir a dependência da relação de interdependência ou de submissão relativa que tem existido ou possa existir entre povos e nações ${ }^{9}$. Assim, para os dependentistas somente o denominado capitalismo industrial tem produzido sociedades propriamente dependentes.

O desenvolvimento e o subdesenvolvimento não são entendidos pela Teoria da Dependência como estados que estejam separados um do outro, sem relação alguma. Contrariamente, sua ligação é muito estreita desde que fazem parte de um único processo que os abarca: a expansão internacional do capital.

Celso Furtado afirma que se deve entender "O problema do subdesenvolvimento como uma realidade histórica, conseqüência da difusão da técnica moderna no processo de constituição de uma economia em escala mundial. O subdesenvolvimento deve ser compreendido como um fenômeno da história moderna, paralelo ao desenvolvimento, como um dos aspectos da difusão da revolução industrial. Desta forma, seu estudo não pode ser realizado isoladamente, como uma 'fase' do processo de desenvolvimento, etapa que deve ser necessariamente superada, sempre que atuassem conjuntamente certos fatores. Pelo próprio fato de ser paralelo às economias desenvolvidas, ou seja, das economias que provocaram e dirigiram o processo de formação de um sistema econômico da base mundial, os atuais países subdesenvolvidos não podem repetir a experiência dessas economias." 10

Com referência ao mesmo ponto, Fernando Henrique Cardoso afirma que "o conceito de 'subdesenvolvimento' não corresponde ao de 'sociedades tradicionais' ou ao de 'sociedades arcaicas', nem mesmo ao de sociedades (ou economias) agrárias. A noção de sociedade subdesenvolvida só se torna significativa quando há uma referência

\footnotetext{
${ }^{8}$ Heraldo Muñoz, "Cambio y Continuidad en el Debate sobre la Dependencia y el Imperialismo". Estudios Internacionales, V.11, No44, octubre-diciembre 1978, p. 89.

${ }^{9}$ Convém lembrar que a interdependência é definida por Keohane e Nye como "situações caracterizadas por efeitos recíprocos entre países ou entre atores em diferentes países.", em Power and Interdependence. World Politic in Transition, Boston: Little, Brown and Company, 1977, p. 8.

${ }^{10}$ Celso Furtado, Subdesarrollo y Estancamiento en America Latina, Buenos Aires: EUDEBA, 1966, pp. $11-12$.
} 
implícita a uma relação determinada entre um tipo particular de sociedade com outra 'desenvolvida'." 11

A evolução do capitalismo industrial só foi possível na metrópole na medida em que contou com os baixos custos das matérias-primas e da mão de obra dos satélites, produzindo com isto o desenvolvimento do centro e o subdesenvolvimento da periferia.

Em síntese, a dependência refere-se a uma condição estrutural na qual um sistema fracamente integrado não consegue completar seu ciclo econômico, dentro do sistema capitalista internacional, exceto por uma exclusiva ou limitada confiança num complemento externo.

Outro conceito que se encontra presente na maioria dos autores da dependência é o de "fragmentação interna". Este afirma que não é coerente a estruturação econômica interna da sociedade dependente. "A suposição é que a economia dependente está internamente desarticulada, suas partes só estão fracamente conectadas e as ligações setoriais estão pobremente estabelecidas." 12

Este conceito de fragmentação interna não deve ser confundido com o conceito de "sociedade dual", que se encontra em autores não dependentistas. Este conceito faz referência à existência, dentro de uma mesma economia nacional, de um setor agrícola que pode ser qualificado de feudal, paralelamente à existência de centros urbanos com características de uma economia capitalista.

Diferentemente, o conceito de fragmentação interna implica que os setores pobres e marginais estão funcionalmente ligados aos segmentos mais desenvolvidos e modernizados da sociedade. Com isto não se quer dizer que são setores pobres e marginais da sociedade por estarem excluídos do processo econômico, ao contrário, são assim justamente por estarem nele incluídos.

Ademais, o conceito de fragmentação interna afirma que a dualidade ou fragmentação não se dá majoritariamente entre ricos e pobres ou entre setores modernizados e abandonados, mas entre os próprios setores modernizados. A economia de uma sociedade dependente não é um todo harmônico, mas uma rede de interesses contrapostos, que influi negativamente na independência e fortalecimento econômico do

\footnotetext{
${ }^{11}$ Fernando Henrique Cardoso, Cuestiones de Sociologia del Desarrollo de América Latina, Santiago: Editorial Universitária, 1968, p. 33.

${ }^{12}$ James Caporaso, op. cit., p. 50.
} 
país. Furtado diz que "É a heterogeneidade tecnológica entre setores ou departamentos de uma mesma economia o que caracteriza o subdesenvolvimento." 13

Desta maneira, por exemplo, Enzo Faletto afirma, a respeito da América Latina, que: "O problema do subdesenvolvimento econômico não é só um problema de crescimento econômico, mas, fundamentalmente, um problema de integração de uma economia nacional." 14

Quando se quer sintetizar as idéias centrais que formam o núcleo da Teoria da Dependência, surgem alguns pontos que se encontram presentes, de alguma maneira, nos principais autores desta teoria.

O mais importante destes pontos afirma que o subdesenvolvimento contemporâneo dos países pobres é o resultado histórico da expansão capitalista "e do estabelecimento de uma divisão internacional do trabalho que modelou as economias periféricas de acordo com as necessidades do capitalismo mundial" ${ }^{15}$. Isto quer dizer que estes países passaram a subdesenvolvidos depois do surgimento do capitalismo, quer dizer, não se deve entender o subdesenvolvimento como uma etapa prévia do capitalismo.

Nas palavras de Celso Furtado: "Por tanto, o subdesenvolvimento é um processo histórico autônomo e não uma etapa pela qual deviam ter passado, necessariamente, as economias que já alcançaram um grau superior de desenvolvimento. Para captar a essência do problema das atuais economias subdesenvolvidas é necessário considerar esta peculiaridade." 16

Em segundo lugar, outra das idéias básicas, que encontramos nos teóricos da dependência, expressa que o esquema mundial centro-periferia tende à sua reprodução no sistema nacional; de maneira que surgem "fluxos de maior valor a partir do campo para as zonas urbanas." ${ }^{17}$, do mesmo modo como surgem da periferia para os centros.

Uma terceira suposição é a não existência de uma burguesia nacional progressista. O setor industrial nacional está estreitamente ligado aos seus homônimos

\footnotetext{
${ }^{13}$ Celso Furtado, Desarrollo y Subdesarrollo. Buenos Aires: Eudeba, 1964, p. 178.

${ }^{14}$ Enzo Faletto. Burocracia y Estado em América Latina. Material de Discusión, Programa Flacso, Santiago, No14, abril 1981, p. 13.

${ }^{15}$ Heraldo Muñoz, op. cit., p. 97.

${ }^{16}$ Celso Furtado, Desarrollo y..., op. cit., p. 165.

${ }^{17}$ Heraldo Muñoz, op. cit., p. 98.
} 
dos países capitalistas adiantados e seu interesse é "preservar as estruturas do capitalismo transnacional que os beneficia." 18

Desta maneira, passam a se compreendidos os diferentes tipos de ajuda, econômica e militar, a penetração tecnológica, a transferência de tecnologia e os investimentos diretos de capital realizados pelas transnacionais, recursos estes utilizados pelas economias centrais para manter e fortalecer as relações de dependência.

Por exemplo, dizem Caputo e Pizarro, "A ação do capital estrangeiro gera nas economias para onde se dirige, particularmente subdesenvolvidas, um conjunto de distorções, dentre elas, o desenvolvimento de atividades inadequadas ao atual desenvolvimento em que se encontram as forças produtivas, a monopolização e a estrangeirização crescentes das decisões etc. Assim, estrutura-se uma economia dependente, limitada e condicionada em seu subdesenvolvimento aos centros do sistema." 19

Por último, os teóricos da dependência coincidem em que a solução para o problema do subdesenvolvimento passa pela eliminação das estruturas capitalistas dos países dependentes e pela criação de uma ordem socialista. Como diz Gunder Frank, existe uma "única e verdadeira estratégia para o desenvolvimento: a revolução armada e a construção do socialismo." 20

A partir de outra corrente da Teoria da Dependência, num tom mais moderado, Fernando Henrique Cardoso e Enzo Faletto afirmam: "criticamos também àqueles que esperam um desenvolvimento capitalista das economias periféricas, para solucionar problemas tais como a distribuição de propriedades, o emprego, melhor redistribuição da renda e melhores condições de vida para a população. Ainda nas economias desenvolvidas esses problemas continuam sem solução, como o provam os portoriquenhos, os negros e os brancos pobres na América do Norte." ${ }^{21}$. Os mesmos autores acrescentam que "Não é realista imaginar que o desenvolvimento capitalista resolvera problemas básicos para a maioria da população. Em definitivo, o que tem que ser discutido como alternativa não é uma consolidação do Estado e uma realização plena do

\footnotetext{
${ }^{18} \mathrm{Ibid}$.

${ }^{19}$ Caputo y Pizarro, Imperialismo, Dependencia y Relaciones Económicas Internacionales, Santiago: CESO, U. de Chile, 1970, p. 324.

${ }^{20}$ André Gunder Frank, op. cit., p. 170.

${ }^{21}$ Fernando Henrique Cardoso e Enzo Faletto, "Repensando Dependência e Desenvolvimento na América Latina". Economia e Movimentos Sociais na América Latina, Bernardo Sorj, Fernando H. Cardoso e Mauricio Font (eds.), São Paulo: Editora Brasiliense, 1985, p. 29.
} 
“capitalismo autônomo", mas sim a sua superação. A questão relevante, então, é como construir caminhos para o socialismo." 22

\section{Conclusão}

As rápidas e qualitativas mudanças no mundo contemporâneo, tanto do sistema político e econômico internacional, quanto no âmbito da cultura e das ideologias, tornaram os postulados da Teoria da Dependência, ferramentas pouco adequadas para refletir corretamente a estrutura e os processos que ocorrem na sociedade nacional e na sociedade internacional.

O sistema internacional tem ficado cada vez mais interdependente. Isto é, os atores do sistema já não são somente os estados, surgindo também relações transgovernamentais e transnacionais. Não existe uma clara hierarquia nos temas da agenda internacional e a força militar é hoje menos importante como um instrumento de política efetivo. A interdependência na política mundial caracteriza-se por uma situação na qual se observam efeitos recíprocos entre os países e entre atores em diferentes países.

Um sistema como o descrito acima é muito mais complexo do que uma visão maniqueísta do mundo dividido entre dominadores e dominados, como a que encontramos em alguns dos expoentes mais radicais da dependência como Frank e Theotônio dos Santos.

Em um sistema interdependente como o atual, a soberania e a autonomia absoluta não existem. Todos os países, sejam eles grandes ou pequenos, encontram-se condicionados pelo sistema internacional. A autonomia relativa é uma realidade inerente ao sistema internacional contemporâneo. Desenvolver políticas com o objetivo de conquistar uma autonomia absoluta pode ter graves conseqüências para os países que optarem por este caminho, sobre tudo se estes são relativamente pequenos.

Ainda, as forças que atuam no capitalismo não são necessariamente reacionárias, no sentido de contrárias à modernização das economias perif6ericas; sendo um exemplo disto as pujantes economias do sudeste asiático.

\footnotetext{
${ }^{22}$ Ibid., p. 30.
} 
Observa-se certa convivência e obtenção de benefícios mútuos entre empresas transnacionais, governos e classes dominantes locais. Quando aumenta a produtividade material de uma sociedade devido à industrialização capitalista, isto redunda em um benefício potencial para toda a sociedade, incluindo a classe trabalhadora.

O sistema internacional atual, interdependente e fundamentado principalmente no comércio, oferece uma maior margem de manobra aos países periféricos, o que pode levar, enquanto implementadas políticas adequadas para cada país, a possibilidades de maior autonomia e de novos espaços para avançar no desenvolvimento dos países localizados em regiões periféricas.

Apesar do dito acima, dentro de uma perspectiva histórica, é correto identificar na Teoria da Dependência perspicazes e interessantes conceitos que podem ajudar no entendimento da complexa relação entre os países periféricos e centrais do sistema mundial, sempre tendo presente a rápida e complexa evolução do mesmo.

\section{Referências Bibliográficas}

CAPORASO, James e ZARE, Behrouz. "An Interpretation and Evaluation of Dependence Theory", em Heraldo Muñoz (ed.), From Dependency to Development: Strategies to Overcome Underdevelopment and Inequality, Boulder, Colorado: Westview Press, 1981.

CAPUTO, Orlando e PIZARRO, Roberto. Imperialismo, Dependencia y Relaciones Económicas Internacionales, Santiago: CESO, U. de Chile, 1970.

CARDOSO, Fernando Henrique. Cuestiones de Sociologia del Desarrollo de América Latina, Santiago: Editorial Universitária, 1968.

CARDOSO, Fernando Henrique e FALETTO, Enzo. "Repensando Dependência e Desenvolvimento na América Latina". Economia e Movimentos Sociais na América Latina, Bernardo Sorj, Fernando H. Cardoso e Mauricio Font (eds.), São Paulo: Editora Brasiliense, 1985.

FALETTO, Enzo. Burocracia y Estado em América Latina. Material de Discusión, Programa Flacso, Santiago, No14, abril 1981. 
FRANK, André Gunder. Lumpenburguesía: Lumpendesarrollo. Santiago: Editorial Prensa Latinoamericana, 1970.

FURTADO, Celso. Subdesarrollo y Estancamiento em America Latina, Buenos Aires: Eudeba, 1966.

FURTADO, Celso. Desarrollo y Subdesarrollo. Buenos Aires: Eudeba, 1964

KEOHANE, Robert e NYE, Joseph. Power and Interdependence. World Politic in Transition, Boston: Little, Brown and Company, 1977.

MUÑOZ, Heraldo. "Cambio y Continuidad em el Debate sobre la Dependencia y el Imperialismo". Estudios Internacionales, V.11, N44, octubre-diciembre 1978.

SANTOS, Theotônio dos. La Crisis Norteamericana y América Latina, Santiago: Editorial Prensa Latino-americana, 1971.

TOMASSINI, Luciano. Teoría y Práctica de la política Internacional, Santiago: Ediciones Universidad Católica de Chile, 1989. 